CIVICS EDUCATION AND SOCIAL SCIENSE JOURNAL (CESSJ)

Volume 3 Nomor 2 Edisi Bulan Desember 2021

\title{
Kapasitas Guru Memahami Psikologi Pendidikan dan Karakter Siswa Selama Pandemi Covid-19
}

\author{
Meidawati Suswandari ${ }^{1}$, Moefty Mahendra ${ }^{2}$, Tri Sutrisno ${ }^{3}$, dan Koko Prasetyo ${ }^{4}$ \\ ${ }^{1234}$ PGSD, Universitas Veteran Bangun Nusantara, Sukoharjo \\ Email: ${ }^{1}$ moetis_meida@yahoo.co.id; ${ }^{2}$ mahendramoefty@gmail.com; ${ }^{3}$ \\ triynwasutrisno@gmail.com; ${ }^{4}$ kokoprasetyo_15@yahoo.co.id
}

\begin{abstract}
This study aims to describe the capacity of teachers to understand educational psychology and student character during the Covid-19 pandemic. This research method uses literature study. The object of this research is the capacity of teachers and the psychology of children's education. The research subject is the teacher. The data collection tool in this research is to search for journals contained in several electronic media such as digital libraries, internet, through Google Scholar. The data analysis technique used in this research is annotated bibliography analysis. The results show that the capacity of teachers to understand the psychology of children's education during the Covid-19 pandemic can be realized through problem solving methods. The steps of the problem solving method in the psychological education of children are carried out in 4 ways, namely problem orientation, problem identification, alternative choices, decision making, and verification. Meanwhile, the learning provided by teachers during the pandemic in character education is making learning modules containing character, teachers can be able to create interesting online learning content for students, giving independent assignments containing character, implementing character education in online learning, good communication between teachers with parents, and provide rewards for positive activities carried out by students to motivate.
\end{abstract}

Keywords: children, teacher capacity, character, educational psychology

\begin{abstract}
Abstrak
Penelitian ini memiliki tujuan untuk mendeskripsikan kapasitas guru memahami psikologi pendidikan dan karakter siswa selama pandemic Covid-19. Metode penelitian ini menggunakan studi pustaka. Obyek penelitian ini adalah kapasitas guru dan psikologi pendidikan anak. Subyek penelitian adalah guru. Alat pengumpulan data dalam penelitian ini adalah dengan melakukan penelusuran jurnal-jurnal yang terdapat pada beberapa media elektronik seperti digital library, internet, dengan melalui Google Cendekia. Teknik analisis data yang digunakan dalam penelitian ini adalah analisis anotasi bibliografi (annotated bibliography). Hasil penelitian menunjukan bahwa kapasitas guru memahami psikologi pendidikan anak selama pandemic Covid-19 dapat diwujudkan melalui metode pemecahan masalah. Adapun langkah-langkah dari metode pemecahan masalah dalam psikologis pendidikan anak dilakukan melalui 4 cara, yaitu Orientasi masalah, Identifikasi masalah, Pilihan Alternatif, Pengambilan Keputusan, dan Verifikasi. Sementara itu, pembelajaran yang diberikan oleh guru selama pandemi dalam pendidikan karakter yaitu membuat modul pembelajaran bermuatan karakter, guru dapat dapat membuat konten pembelajaran online yang menarik bagi siswa,
\end{abstract}

JURNAL PROGDI PPKn, FKIP UNIVET BANTARA SUKOHARJO BEKERJA SAMA DENGAN

ASSOSIASI PROFESI PENDIDIKAN PANCASILA DAN KEWARGANEGARAAN (AP3KNI) JAWA TENGAH 
CIVICS EDUCATION AND SOCIAL SCIENSE JOURNAL (CESSJ)

Volume 3 Nomor 2 Edisi Bulan Desember 2021

pemberian tugas mandiri yang bermuatan karakter, penerapan pendidikan karakter dalam pembelajaran online, komunikasi yang baik antara guru dengan orang tua, dan memberikan reward atas kegiatan positif yang dilakukan siswa untuk memotivasi.

Kata kunci: anak, kapasitas guru, karakter, psikologi pendidikan

\section{Pendahuluan}

Sebagai seorang guru pada dasarnya memiliki kapasitas memfasilitasi terjadinya perkembangan peserta didik karena peserta didik merupakan subjek pembelajaran yang sedang mengembangkan dirinya. Pentingnya interaksi antara pendidik dan peserta didik terjadi saling mempengaruhi. Peran pendidik salahsatunya memilih metode pembelajaran yang tepat dan sesuai kebutuhan peserta didik. Psikologi pendidikan inilah yang menjadikan penting yang harus dipahami oleh pendidik. Psikologi dimaknai "psyche" yang artinya jiwa, dan "logos" yang artinya ilmu pengetahuan. Jadi secara etimologi (menurut arti kata) psikologi artinya ilmu yang mempelajari tentang jiwa, baik mengenai macam-macam gejalanya, prosesnya maupun latar belakangnya, atau disebut dengan ilmu jiwa (Sakerebau, 2018; Soeparno, 2016).

Berbicara tentang ilmu jiwa, terlebih dahulu kita harus dapat membedakan antara nyawa dengan jiwa. Nyawa adalah daya jasmaniah memiliki ketergantungan pada hidup jasmani dan menimbulkan perbuatan badaniah, yaitu perbuatan yang di timbulkan oleh proses belajar. Misalnya: insting, refleks, nafsu dan sebagainya. Jika jasmani mati, maka mati pulalah nyawanya (Nurjan, 2016; Thamaria, 2016).

Selain itu, psikologi pendidikan dapat dipandang sebagai ilmu pengetahuan praktis, yang berusaha utnuk menerangkan bealajar sesuai dengan prinsip-prinsip yang ditetapkan secara ilmiah dan fakta-fakta sekitar tingkah laku manusia. Psikologi menerangkan bagaimana perkembangan seseorang berlangsung dalam hubungannya dengan belajar. Pendidikan berusaha untuk mempelajari apa-apa yang dibutuhkan dan harus dipelajari; psikologi pendidikan memperhatikan mengapa dan kapan masa-masa yang baik belajar. Tingkat keberhasilan dalam mengajar tergantung pada besar dan luasnya kesanggupan merangsang kearah tercapainya kemajuan-kemajuan dalam perkembangan, penampilan kebutuhan-kebutuhan dan memberi arah potensi-potensi pembawaan para pelajar (Nurliani, 2016).

Berdasarkan konsep di atas, dapat disimpulkan bahwa psikologi pendidikan adalah ilmu yang mempelajari tentang jiwa dan tingkah laku yang bersifat psikomotor, tingkah laku berfikir, berkeyakinan, berperasaan untuk mempelajari perkembangan belajar, motivasi, pengajaran dan permasalahan yang muncul dalam dunia pendidikan.

Psikologi pendidikan sebagai ilmu yang mempelajari tentang jiwa dan tingkah laku untuk mempelajari perkembangan belajar, motivasi, pengajaran dan permasalahan yang muncul dalam dunia pendidikan khususnya siswa. Kapasitas guru dalam hal ini sangat berpengaruh pada psikologis siswanya. Kapasitas siswa dan kapasitas guru saling timbal balik dalam pembelajaran. Karena pembelajaran yang dimaksud 
merupakan proses edukatif yang melibatkan pendidik dan peserta didik sebagai pelaku utamanya. Pendidik berkapasitas sebagai fasilitator terjadinya perkembangan peserta didik dan peserta didik merupaka subjek pembelajaran yang sedang mengembangkan dirinya.

Melibatkan siswa dalam pembelajaran di kelas untuk kondisi saat ini, tidaklah mudah. Apalagi pemerintah sudah mengimbau untuk bekerja, belajar, dan beribadah dari rumah untuk menekan angka pasien yang terpapar COVID-19. Menteri Nadiem Anwar Makarim menerbitkan Surat Edaran Nomor 3 Tahun 2020 pada Satuan Pendidikan dan Nomor 36962/MPK.A/HK/2020 tentang Pelaksanaan Pendidikan dalam Masa Darurat Coronavirus Disease (COVID-19) maka kegaiatan belajar dilakukan secara daring (online) dalam rangka pencegahan penyebaran coronavirus disease (COVID-19). Dengan munculnya pandemik COVID-19 kegiatan belajar mengajar yang semula dilaksanakan di sekolah kini menjadi belajar di rumah melalui daring. Pembelajaran daring dilakukan dengan disesuaikan kemampuan masingmasing sekolah. Belajar daring (online) dapat menggunakan teknologi digital seperti google classroom, rumah belajar, zoom, video converence, telepon atau live chat dan lainnya (Mubarizi et al., 2020).

Pada satu sisi masa pandemic Covid-19, kapasitas guru seolah-olah berkurang karena tanpa adanya interaksi langsung dengan siswa/anak di kelas. Karena siswa lebih banyak di rumah dengan kebijakan Belajar Dari Rumah oleh pemerintah karena menimbang dan mengingat akan kondisi perkembangan kasus dan pasien Covid-19. Namun, hal itu tidak memungkiri bahwa guru masih memiliki kapasitas dalam psikologis pendidikan anak. Seperti yang diungkap oleh Mahmudah (2020) dalam penelitiannya yang berjudul "Pengaruh Pembelajaran Daring terhadap Psikologis Siswa Terdampak Social Distancing Akibat Covid 19". Hasil penelitian menunjukan bahwa Hasil penelitian menunjukkan bahwa pembelajaran daring tidak efektif dikalangan siswa karena psikologis siswa terganggu Penerapan tersebut saat ini memegang peran penting dalam dunia pendidikan islam, tetapi penerapan sistem pembelajaran daring tidak semudah yang dibayangkan, terdapat beberapa aspek yang harus dipenuhi terlebih dahulu. Segi praktisnya, pembelajaran daring sangat efektif untuk pembelajaran ditengah covid 19. Namun, tidak untuk psikologis siswa. Pembelajaran daring tersebut dapat dikembangkan menjadi pembelajaran yang lebih efektif dengan memperhatikan psikologis siswa terdampak social disctancing.

Demikian pula dengan karakter siswa selama pandemi covid-19. Karakter yaitu hubungan manusia dengan alam yang digerakan oleh naluri dasar atau insting dan budaya setempat mempengaruhi pola karakter manusia. Tujuan pendidikan karakter ialah pembentukan generasi akan dating yang memiliki kecerdasan intelektual, dan memiliki keterampilan hidup. Melalai pendidikan karakter tertanamkan pembiasaan yang baik sehingga siswa memahami perlikau baik dan buruk, perilaku salah dan benar. Penanaman dan pembentukan karakter tidak lepas daro pembimbingan dan pengarahan orang sekitar melalui pembiasaan, penguatan dan keteladanan (D. A. Dewi et al., 2021; Rachman \& Budi, 2020; Saputri, T N \& Muknim, 2021; Sopiah, 2021).

JURNAL PROGDI PPKn, FKIP UNIVET BANTARA SUKOHARJO BEKERJA SAMA DENGAN ASSOSIASI PROFESI PENDIDIKAN PANCASILA DAN KEWARGANEGARAAN (AP3KNI) JAWA TENGAH 
Menurut Lickona (Daga, 2021; Mahmudah, 2020; Mubarizi et al., 2020; Purandina, I P \& Winaya, 2020; Suriadi \& Ahmad, 2021) menyebutkan tujuh unsurunsur karakter esensial dan utama yang harus ditanamkan kepada peserta didik yang meliputi: 1. Perilaku jujur (honesty). 2. Welas asih (compassion); 3. Keberanian (courage); 4. Rasa kasih sayang (kindness); 5. Mengotrol pribadi (self-control); 6. Perilaku saling kerja sama (cooperation).

Satu hal dalam kasus dari hasil penelitian Massie (2021) bahwa adanya penurunan karakter siswa selama pembelajaran daring di masa pandemi. Faktor penurunan tersebut dikarenakan kemajuan teknologi, kurangnya adaptasi, kurangnya pengawasan guru dan orang tua, dan kurangnya kesadaran diri.

Penurunan karakter siswa menjadi peran guru dalam memfasilitasi perkembangan psikologi pendidikan pada peserta didik ini. Hasil penelitian Santika (2020) menunjukan bahwa pembelajaran dirancang dengan membiasakan disiplin belajar, tanggung jawab dalam menyelesaikan tugas, menanamkan pola hidup sehat, kejujuran dan sikap religius. Guru perlu kreatif menyusun pembelajaran dengan tetap mempertimbangkan pendidikan karakter di masa pandemi Covid-19. Pendidikan karakter di masa pandemi akan memberikan pola hidup berkarakter sejak dini di mana pun dan dalam kondisi apapun.

Oleh sebab itu, penting rasanya dalam mengkaji kapasitas guru dalam memahami psikologi pendidikan dan karakter siswa selama pandemi Covid-19. Adanya kapasitas guru dengan memahami psikologi pendidikan anak ini diharapkan memberikan manfaat sebagai pendidik agar dapat memahami tingkahlaku dan jiwa peserta didik/siswa. Karena seorang guru dapat menciptakan roh pembelajaran adalah adanya interaksi guru dan siswa. Interaksi dalam peristiwa belajar mengajar mempunyai arti yang lebih luas, tidak sekedar hubungan antara guru dengan siswa, tetapi berupa interaksi edukatif. Dalam hal ini bukan hanya penyampaian pesan berupa materi pelajaran, melainkan penanaman sikap dan nilai pada diri siswa yang sedang belajar.

\section{Metode Penelitian}

Penulisan ini dilakukan melalui studi pustaka. Studi pustaka adalah penelitian yang dilakukan dengan mengkaji mengenai konsep dan teori yang digunakan berdasarkan literatur yang tersedia, yang diantaranya artikel-artikel yang dipublikasikan dalam jurnal ilmiah yang berisi teori-teori yang relevan dengan masalah-masalah penelitian. Obyek penelitian ini adalah kapasitas guru, karakter dan psikologi pendidikan siswa. Subyek penelitian adalah guru dan siswa.

Alat pengumpulan data dalam penelitian ini adalah dengan melakukan penelusuran jurnal-jurnal yang terdapat pada beberapa media elektronik seperti digital library, internet, dengan melalui Google Cendekia. Kata kunci yang digunakan dalam penelusuran pada jurnal dan buku yang relevan dalam penelitian studi pustaka ini adalah "kapasitass guru", psokologi pendidikan", dan "siswa", serta "karakter". Oleh sebab itu, alat pengumpulan data dalam artikel ini dengan menggunakan jurnal-jurnal yang terdapat pada Google Cendekia atau Google Scholar. 
Teknik analisis data yang digunakan dalam penelitian ini adalah analisis anotasi bibliografi (annotated bibliography) yang artinya suatu kesimpulan sederhana dari suatu artikel, buku, jurnal, atau beberapa sumber tulisan lain. Sedangkan bibliografi diartikan sebagai suatu daftar sumber dari suatu topik.

\section{Hasil dan Pembahasan}

Guru dalam menjalankan kapasitasnya sebagai pendidik bagi peserta didik/siswanya dituntut memahami tentang berbagai aspek perilaku dirinya maupun perilaku orang-orang yang terkait dengan tugasnya, terutama perilaku peserta didik dengan segala aspeknya, sehingga dapat menjalankan tugas dan kapasitasnya secara efektif, yang pada gilirannya dapat memberikan kontribusi nyata bagi pencapaian tujuan pendidikan di sekolah. Seperti yang diungkapkan oleh Muhibbin Syah (2003) mengatakan bahwa "diantara pengetahuan-pengetahuan yang perlu dikuasai guru dan calon guru adalah pengetahuan psikologi terapan yang erat kaitannya dengan proses belajar mengajar peserta didik".

Apalagi pada masa pandemic Covid-19 saat ini, kapasitas guru memiliki peranan yang penting dalam memahami psikologis pendidikan anak. Hasil penelitian Mustakim (2020) yang dilakukan kepada peserta didik SMA Negeri 1 Wajo menunjukan bahwa peserta didik banyak mengalami keluhan psikologis. Keluhan yang paling banyak dialami yakni perasaan ingin semuanya segera berakhir (70\%), mereka juga merasakan kebosanan yang dalam (63,3\%), pusing, (20\%), khawatir (20\%), dan resah $(3,3 \%)$. Namun, ada diantara mereka yang sama sekali tidak merasakan keluhan psikologis $(16,7 \%)$. Data tersebut tersaji dalam grafik berikut ini.

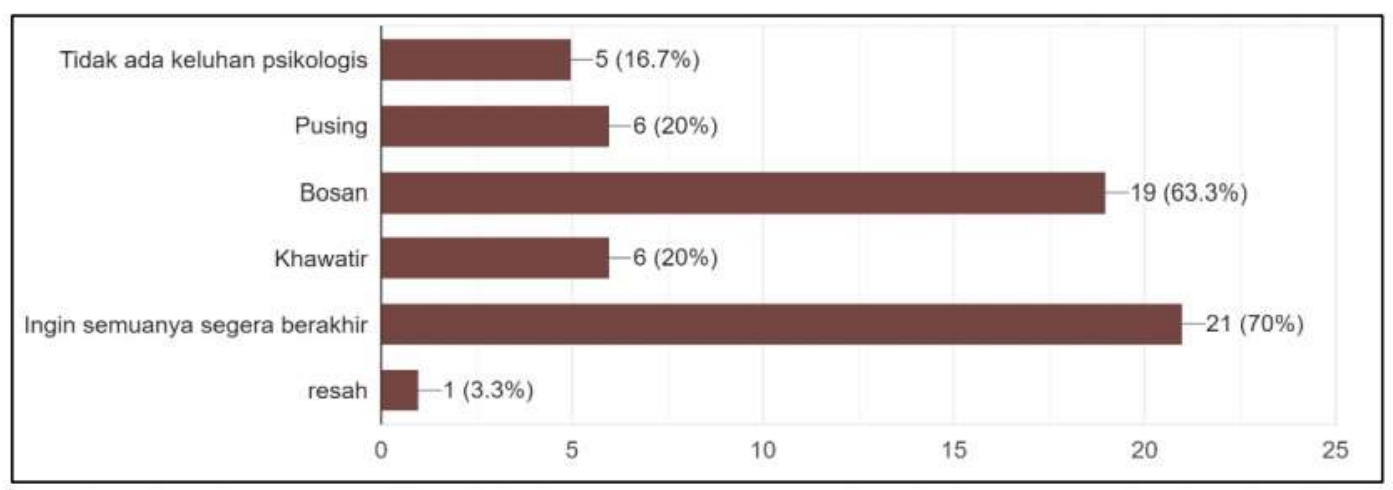

Grafik 1. Keluhan Psikologis yang dialami peserta didik.

Beberapa kasus keluahan yang muncul diatas, menjadikan pentingnya kapasitas guru dalam memahami psikologi pendidikan anak selama pandemic Covid-19. Seperti yang diungkapkan oleh D'zurilla dan Goldfried (Fatchurahman et al., 2018; Rojuli \& Rahayu, 2017; Thahir, 2012) terdapat metode dalam memahami psikologi pendidikan anak. Metode tersebut dinamakan metode pemecahan masalah yang berdasarkan kajian psikologis. Adapun langkah-langkah metode pemecahan masalah tersebut adalah sebagai berikut.

\section{Pertama, Orientasi masalah}

JURNAL PROGDI PPKn, FKIP UNIVET BANTARA SUKOHARJO BEKERJA SAMA DENGAN ASSOSIASI PROFESI PENDIDIKAN PANCASILA DAN KEWARGANEGARAAN (AP3KNI) JAWA TENGAH 
Langkah pertama syaratnya, bahwa siswa mengenali dan menerima masalahnya. Jika siswa menyangkal masalahnya, itu tidak dapat ditangani dengan cara yang memadai. Model pemecahan masalah membantu untuk "menormalkan" keprihatinan siswa. Ini berarti penerimaan masalah sebagai bagian dari kehidupan normal. Konselor yaitu kapasitas guru memberikan dukungan dan perspektif untuk siswa sebagai permulaan untuk mengatasi masalah siswa. Pengakuan dari masalah, bersama dengan masalahnya, membantu konselor untuk menjalin hubungan dengan siswa (Karni, 2014).

Jika dikaitkan dengan siswa maka tugas seorang guru haru memiliki kepekaan/kesadaran diri dan eksplorasi diri dapat merangsang siswa menganai situasi masalah yang dialaminya. Pendekatan dapat dilakukan secara halus seperti tidak terkesan mengintrogasi siswa agar dapat dengan mudah siswa berbicara tanpa adanya rasa cemas.

\section{Kedua, Identifikasi masalah}

Pada langkah ini, guru dan siswa berusaha untuk mengidentifikasi masalah sedetail mungkin. Prosedur penilaian dapat membantu menjelaskan sifat masalah siswa. Misalnya, daftar pembanding masalah atau gejala dapat digunakan untuk menilai tipe dan luasnya masalah siswa. Buku harian pribadi atau log dapat juga digunakan untuk mengidentifikasi situasi di mana masalah terjadi. Kepribadian dapat membantu guru dan siswa untuk mengerti dinamika kepribadian yang mendasari situasi yang bermasalah. Informasi yang diperoleh selama mengidentifikasi masalah siswa dapat digunakan untuk menentukan tujuan konseling.

Identifikasi masalah meningkatkan komunikasi dengan siswa. Siswa akan cenderung terus melakukan konseling jika guru dan siswa setuju pada sifat masalah. Identifikasi masalah juga membantu dalam komunikasi dengan orang lain, seperti sumber-sumber rujukan (Amelisa, 2018; R. Dewi, 2015).

Kapasitas guru dalam tahapan ini adalah mengidentifikasi masalah siswa dari berapa sumber, seperti catatan harian, gejala yang muncul/observasi/pengamatan keseharian siswa.

\section{Ketiga, Pilihan alternatif}

Langkah ketiga, guru dan siswa menghasilkan alternatif untuk mengatasi masalah. Prosedur penilaian memungkinkan guru dan siswa untuk mengidentifikasi alternatif solusi bagi masalah siswa. Misalnya, minat dalam inventory bisa menyarankan alternatif pilihan karir untuk siswa. Penilaian wawancara dapat digunakan untuk menentukan apa teknik yang telah bekerja untuk siswa di masa lalu ketika dihadapkan dengan masalah yang sama. Hasil tes dapat membantu siswa untuk melihat masalah dari sudut yang berbeda. Sebagai contoh, penggunaan instrumen yang mengukur gaya kepribadian siswa dengan menyediakan alternatif untuk melihat perilaku mereka atau perilaku orang lain. Latihan penilaian dapat mengidentifikasi pernyataan siswa secara positif, yang dapat membuka alternatif untuk siswa (Taman \& amp; Hollon, 1988). Guru menggunakan prosedur penilaian untuk membantu siswa dalam menemukan kekuatan yang dapat mereka bangun untuk mengatasi kesulitan atau meningkatkan pengembangan (Duckworth, 1990). 
CIVICS EDUCATION AND SOCIAL SCIENSE JOURNAL (CESSJ)

Volume 3 Nomor 2 Edisi Bulan Desember 2021

\section{Keempat, Pengambilan keputusan}

Pengambilan solusi sebuah masalah dalam pendapat Horan, siswa membutuhkan antisipasi urutan-urutan berbagai alternatif. Menurut teori keputusan klasik, pilihan adalah fungsi dari probabilitas keberhasilan dan keinginan untuk hasil. Persamaan ini menggaris bawahi pentingnya menilai kedua keberhasilan berbagai alternatif dan daya tarik alternatif-alternatif untuk siswa. Siswa biasanya ingin mempertimbangkan adanya alternatif-alternatif yang dapat memaksimalkan kemungkinan hasil yang menguntungkan (Anwar, 2014; Chaniago, 2017).

Guru menggunakan bahan-bahan penilaian untuk membantu siswa menimbang daya tarik dari setiap alternatif dan kemungkinan mencapai setiap alternatif. Sebagai contoh, nilai-nilai klarifikasi latihan dapat membantu siswa dalam mengevaluasi daya tarik berbagai alternatif. Menurut Goldman dan Cochran bahwa berdasarkan pengalaman penggunaan tes psikologi dalam lembaga konseling yang disajikan dalam tabel yang menunjukkan tingkat keberhasilan untuk orang-orang dengan perbedaan bentuk berbagai jenis nilai tes atau karakteristik dapat membantu siswa untuk memperkirakan peluang sukses dalam kursus-kursus yang berbeda dari tindakan. Pertimbangan dalam pengambilan keputusan memungkinkan siswa untuk membandingkan keinginan dan kelayakan dari berbagai alternative (El Fiah, 2015).

Kapasitas guru selanjutnya adalah mengevaluasi masalah siswa melalui berbagai alternatif seperti tes psikologi dan bimbingan secara konseling pada siswa untuk memperkirakan tindakan berikutnya dalam mengatasi masalah yang dialami siswa. Sehingga tindakan yang akan diberikan pada siswa tidak dilakukan dengan gegabah dan seorang guru dalam mengambil keputusan memiliki dasar tertentu.

\section{Kelima, Verifikasi}

Guru perlu mengevaluasi efektivitas Meskipun data asesmen membantu siswa untuk membuat keputusan, siswa seharusnya tidak mengharapkan untuk mendapatkan kepastian atau untuk menghindari. Subyektifitas di dalam pilihan mereka (Gelatt, 1989). Pengetahuan terbatas dan masa depan tidak pasti. Untuk alasan ini, siswa harus didorong untuk menjadi fleksibel dan imagi asli dalam pengambilan keputusan mereka. Guru harus membantu siswa untuk memperluas sumber-sumber mereka informasi dan cara di mana informasi yang diproses (Rizkia, 2018).

Setiap orang sangat bervariasi dalam gaya pengambilan keputusan mereka. Jenis rasional menekankan logika dalam sistematis mengumpulkan data untuk sampai pada keputusan. Mereka dapat mengumpulkan data untuk mengkonfirmasi pilihan mereka telah membuat. Untuk memastikan perspektif yang luas, siswa harus diajarkan untuk menggunakan kedua gaya pengambilan keputusan dalam memperoleh data dan menyelesaikan masalah (Rizkia, 2018). Kapasitas guru melalui asesmen yang telah diperolehnya kemudian mengambil sebuah keputusan dilanjutkan pada memverifikasi atas dasar keputusannya agar dapat dipertanggungjawabkan. Verifikasi data ini memungkinkan kepastian tindakan yang akan diberikan pada siswa dalam menyelesaikan masalah.

Kelima langkah dalam mengatasi psikologi pendidikan siswa yang dilakukan oleh guru juga perlu pertimbangan secara khusus dalam hal pendidikan karakter.

JURNAL PROGDI PPKn, FKIP UNIVET BANTARA SUKOHARJO BEKERJA SAMA DENGAN

ASSOSIASI PROFESI PENDIDIKAN PANCASILA DAN KEWARGANEGARAAN (AP3KNI) JAWA TENGAH 
Dampak pembelajaran selama pandemi pada karakter siswa yakni sekitar 50\% perilaku religi, $50 \%$ perilaku jujur, $45 \%$ perilaku toleransi, $45 \%$ perilaku disiplin, $45 \%$ perilaku kerja keras, $45 \%$ perilaku kreatf, $40 \%$ perilaku mandiri, $60 \%$ perilaku memiliki rasa ingin tahu, $50 \%$ perilaku cinta tanah air, $40 \%$ perilaku gemar membaca, $60 \%$ perilaku peduli lingkungan, dan $40 \%$ perilaku bertanggung jawab (Sopiah, 2021).

Adanya penurunan karakter selama pembelajaran daring/online ini perlu strategi penerapan pendidikan Karakter saat pandemi COVID-19. Song, Singleton, Hill \& Koh (Anwar, 2014; El Fiah, 2015; Mustakim, 2020; Rizkia, 2018) menyebutkan bahwa faktor yang memengaruhi keberhasilan pembelajaran online meliputi: Desain Kursus (Course Design), Motivasi Pembelajar (Learner Motivation), Manajemen Waktu (Time Management). (1). Desain Kursus (Course Design) Desain pembelajaran online selama pandemi bisa dilakukan dengan membuat modul pembelajaran bermuatan karakter. Guru dapat menentukan pengantar modul, tujuan pembelajaran, indikator karakter yang harus di capai, instrument pengukuran tiap pertemuan, asesmen penilaian akhir pembelajaran, refleksi kegiatan pembelajaran. Pembelajaran yang dilakukan dapat dilakukan dengan menggunakan sinkronus dan asinkronus sesuai prinsip blanded learning. (2). Motivasi Pembelajar (Learner Motivation) Motivasi dalam pembelajaran online akan dipengaruhi oleh motivasi intrinsik dan ekstrinsik. Dalam pembelajaran yang bermuatan karakter maka perlu ditanamkan konsep pembelajaran sepanjang hayat. Artinya siswa harus diarahkan untuk nyaman belajar dimanapun dan kapanpun. Pada masa Pandemi COVID-19 siswa harus menerima kenyataan bahwa proses kegiatan pembelajaran dilakukan dirumah (School From Home). Guru dapat dapat membuat konten pembelajaran online yang menarik bagi siswa. Materi diusahakan tidak difokuskan pada interaksi online secara monoton. Kegiatan pembelajaran dapat divariasikan dengan kegiatan tugas mandiri yang mampu mengasah karakter siswa. (3). Manajemen Waktu (Time Management) Pengelolaan waktu belajar selama Pandemi COVID- 19 dapat dilakukan sesuai jadwal pembelajaran. Guru harus mempertimbangkan bagaimana mengukur indikator karakter yang ingin dicapai dalam pembelajaran onlne. Factor lain yang harus diperhatikan adalah berapa durasi ideal siswa akan tertarik mengikuti pembelajaran online. Hal ini dilakukan agar siswa tidak mengalami kejenuhan dalam peroses pembelajaran. Hal lain harus yang diperhatikan juga adalah kegiatan yang dilakukan siswa seusai mengikuti kegiatan pembelajaran online. Ada kencenderungan siswa akan menghabiskan waktu luang untuk bermain game dan bermain sosial media di samartphone. Fenomena ini perlu difasilitasi dengan pemberian tugas mandiri yang bermuatan karakter. Agar waktu luang dapat digunakan unttuk kegiatan yang mengarah pada penumbuhan karakter. (4) Kenyamanan dengan teknologi online (Comfortabeness With Online Technologies). Teknologi online akan memerankan posisi penting dalam penerapan pendidikan karakter dalam pembelajaran online. Guru dan siswa diharapkan dapat lebih adaptif dengan ketersediaan aplikasi online yang mendukung pembelajaran (Apriyanto et al., 2020).

Selain itu, kapasitas guru dalam penanaman karakter selama pandemi dilakukan melalui beberapa hal. Pertama, melalui komunikasi yang baik antara guru dengan

JURNAL PROGDI PPKn, FKIP UNIVET BANTARA SUKOHARJO BEKERJA SAMA DENGAN ASSOSIASI PROFESI PENDIDIKAN PANCASILA DAN KEWARGANEGARAAN (AP3KNI) JAWA TENGAH 
orang tua. Orang tua mengamati sikap anak selama pembelajaran di rumah. Komunikasi yang baik akan sangat penting dalam proses pembelajaran karena orang tua merupakan mitra sekolah. Kedua, melalui lembar penilaian yang telah disusun oleh guru. Data diambil dari hasil kegiatan belajar siswa, hasil tugas, maupun hasil partisipasi dalam pembelajaran. Ketiga, melalui laporan dalam bentuk foto atau video siswa. Laporan sebagai sarana monitoring dan feedback dari guru kepada siswa. Keempat, guru menyusun kuesioner secara online untuk diisi siswa secara jujur. Kelima, memberikan reward atas kegiatan positif yang dilakukan siswa untuk memotivasi melakukan rangkaian kegiatan-kegiatan positif yang lain (Akhwani \& Romdloni, 2021).

\section{Simpulan}

Guru dalam menjalankan tugas dan kapasitasnya secara efektif dapat memberikan kontribusi yang nyata bagi pencapaian tujuan pendidikan dalam bentuk memahami psikologi pendidikan anak. Kapasitas guru dalam memahami psikologis pendidikan anak selama masa pandemic Covid-19 dapat diwujudkan melalui metode pemecahan masalah. Adapun langkah-langkah dari metode pemecahan masalah dalam psikologis pendidikan anak dilakukan melalui 4 cara, yaitu Orientasi masalah, Identifikasi masalah, Pilihan Alternatif, Pengambilan Keputusan, dan Verifikasi. Adanya pemahaman psikologi pendidikan anak oleh guru dapat bermanfaat bagi guru sebagai pendidik dalam memahami tingkahlaku dan jiwa peserta didik/siswa meski dengan keterbatasan fisik/tidak di kelas tapi melalui pembelajaran daring/virtual.

Sementara itu, pembelajaran yang diberikan oleh guru selama pandemi dalam pendidikan karakter yaitu membuat modul pembelajaran bermuatan karakter, guru dapat dapat membuat konten pembelajaran online yang menarik bagi siswa, pemberian tugas mandiri yang bermuatan karakter, penerapan pendidikan karakter dalam pembelajaran online, komunikasi yang baik antara guru dengan orang tua, dan memberikan reward atas kegiatan positif yang dilakukan siswa untuk memotivasi. Meskipun kapasitas dalam hal pendampingan guru secara langsung yang tidak bisa digantikan dengan media online berupa apapun. Karena pendidikan karakter yang diperoleh anakpun akan berbeda tergantung dari pendidikan karakter yang diperolehnya melalui role model dirumah yakni orangtuanya. Sehingga penting adanya kerjasama guru dengan orang tua untuk menjadi model good character dalam pembentukan karakter anak.

\section{Referensi}

Akhwani \& Romdloni, M. (2021). Indonesian Journal of Primary Education. Indonesian Journal of Primary Education, 5(1), 1-12.

Amelisa, M. (2018). Model Konseling Self-Disclosure. Jurnal Bimbingan Konseling Dan Dakwah Islam, 15(1), 57-67.

Anwar, H. (2014). Proses Pengambilan Keputusan untuk Mengembangkan Mutu Madrasah. Nadwa, 8(1), 37. https://doi.org/10.21580/nw.2014.8.1.569

JURNAL PROGDI PPKn, FKIP UNIVET BANTARA SUKOHARJO BEKERJA SAMA DENGAN

ASSOSIASI PROFESI PENDIDIKAN PANCASILA DAN KEWARGANEGARAAN (AP3KNI) JAWA TENGAH 
CIVICS EDUCATION AND SOCIAL SCIENSE JOURNAL (CESSJ)

Volume 3 Nomor 2 Edisi Bulan Desember 2021

Apriyanto, R. D., Andrianie, S., \& Anggara, G. S. (2020). Implementasi pendidikan karakter di masa pandemi covid-19: Tantangan dan Kontribusi. Prosiding Seminar Nasional FIP 2020, 128-135.

Chaniago, A. (2017). Teknik pengambilan keputusan (pendekatan teori dan studi kasus). Lentera Ilmu Cendeia.

Daga, A. T. (2021). Implementing character education during the covid-19 pandemic at elementary school. Jurnal Primary, 10, 836-851.

Dewi, D. A., Hamid, S. I., Annisa, F., \& Octafianti, M. (2021). Menumbuhkan Karakter Siswa melalui Pemanfaatan Literasi Digital. Pingkan Regi Genika, 5(6), 5249-5257.

Dewi, R. (2015). Komunikasi Terapeutik Konselor Laktasi Terhadap Siswa Relaktasi. Jurnal Kajian Komunikasi, 3(2), 192-211. https://doi.org/10.24198/jkk.vol3n2.9

El Fiah, R. (2015). Bimbingan dan konseling di Sekolah (Vol. 7, Issue 2). LPPM IAIN Raden Intan.

Fatchurahman, M., Triyani Syarif, D. F., \& Turohmi, S. (2018). Efektivitas Layanan Konseling Kelompok Menggunakan Teknik Problem Solving dalam Menurunkan Perilaku Membolos Siswa. Indonesian Journal of Educational Counseling, 2(1), 55-68. https://doi.org/10.30653/001.201821.18

Hadi, I. A. (2017). Peran Penting Psikologi dalam Pendidikan Islam. Nadwa, 11(2), 251. https://doi.org/10.21580/nw.2017.11.2.1304

Karni, A. (2014). Konseling dan Psikoterapi Profesional. Syi'ar, 14(1), 39-52.

Mahmudah, S. R. (2020). Pengaruh Pembelajaran Daring terhadap Psikologis Siswa Terdampak Social Distancing Akibat Covid 19. Jurnal Al - Mau'izhoh, 2(2), $1-14$.

Massie, A. Y. (2021). Dampak Pembelajaran Daring terhadap Pendidikan Karakter Siswa. Jurnal Satya Widya, XXXVII(2), 54-61.

Mubarizi, A. F., Pangestuti, H., Selviana, M., \& Saputri, A. (2020). Dampak Covid-19 Terhadap Kesejahteraan Psikologis ( Psycal-Well-Being ) Selama pembelajaran Daring Di Sekolah Dasar Kabupaten Batang. Jurnal Abdimas, 1, 1-8.

Mustakim. (2020). Efektivitas Pembelajaran Daring Menggunakan Media Online Selama Pandemi Covid-19 Pada Mata Pelajaran Matematika the Effectiveness of E-Learning Using Online Media During the Covid-19 Pandemic in Mathematics. Al Asma: Journal of Islamic Education, 2(1), 112.

JURNAL PROGDI PPKn, FKIP UNIVET BANTARA SUKOHARJO BEKERJA SAMA DENGAN ASSOSIASI PROFESI PENDIDIKAN PANCASILA DAN KEWARGANEGARAAN (AP3KNI) JAWA TENGAH 
CIVICS EDUCATION AND SOCIAL SCIENSE JOURNAL (CESSJ)

Volume 3 Nomor 2 Edisi Bulan Desember 2021

Nurjan, S. (2016). Psikologi Belajar Edisi Revisi. Ponorogo: Wade Group

Nurliani, N. (2016). Studi Psikologi Pendidikan. Jurnal As-Salam, 1(2), 39-51.

Purandina, I P \& Winaya, I. M. (2020). Pendidikan Karakter di Lingkungan Keluarga Selama Pembelajaran Jarak Jauh Pendidikan Karakter di Lingkungan Keluarga Selama Pembelajaran Jarak Jauh pada Masa Pandemi COVID19. Cetta (Jurnal Ilmu Pendidikan), 3(2), 270-290.

Rachman, M., \& Budi, C. (2020). Urgensi Pendidikan Karakter Pada Masa Pandemi Covid 19.

Rizkia, R. (2018). Bimbingan dan Konseling Islam dengan teori rational emotif therapy menggunakan teknik pengambilan keputusan dalam mengatasi dilema pemilihan padangan hidup. Prodi Bimbingan Konseling Islam. https://www.uam.es/gruposinv/meva/publicaciones

jesus/capitulos_espanyol_jesus/2005_motivacion para el aprendizaje Perspectiva alumnos.pdf\%0Ahttps://www.researchgate.net/profile/Juan_Aparicio7/publ ication/253571379_Los_estudios_sobre_el_cambio_conceptual_

Rojuli, S., \& Rahayu, A. (2017). Strategi Pembelajaran untuk Peningkatan Soft Skill dan Kesiapan Kerja. Mer-C Publishing.

Sakerebau, J. (2018). Memahami Peran Psikologi Pendidikan Bagi Pembelajaran. $B I A$ '. Jurnal Teologi Dan Pendidikan Kristen Kontekstual, 1(1), 96-111. https://doi.org/10.34307/b.v1i1.22

Santika, I. W. E. (2020). Pendidikan Karakter pada Pembelajaran Daring. Jurnal IVCEJ, 3(1), 8-19.

Saputri, T N \& Muknim, B. A. (2021). Jurnal basicedu. Jurnal Basicedu, 5(4), 20452053.

Soeparno, K. (2016). Social Psychology: the Passion of Psychology. Buletin Psikologi, 19(1), 16-28. https://doi.org/10.22146/bpsi.11544

Sopiah, C. (2021). Dampak Pembelajaran Online terhadap Pendidikan Karakter Anak Usia Dini. Jurnal Jendela Bunda, 8(2), 21-31.

Sriyanti, L. (2011). Psikologi Belajar. Jakarta. STAIN Salatiga Press.

Supriyanto, D. (2017). Sejarah Singkat Psikologi Pendidikan. MODELING: Jurnal Program Studi PGMI, 4(2), 229-238.

Suriadi, H. J., \& Ahmad, R. (2021). Analisis Problema Pembelajaran Daring Terhadap Pendidikan Karakter Peserta Didik. Edukatif: Jurnal Ilmu Pendidikan 3(1), 165-173.

JURNAL PROGDI PPKn, FKIP UNIVET BANTARA SUKOHARJO BEKERJA SAMA DENGAN

ASSOSIASI PROFESI PENDIDIKAN PANCASILA DAN KEWARGANEGARAAN (AP3KNI) JAWA TENGAH 
CIVICS EDUCATION AND SOCIAL SCIENSE JOURNAL (CESSJ)

Volume 3 Nomor 2 Edisi Bulan Desember 2021

Tas'adi, R. (2014). Hakekat dan konsep dasar psikologi pendidikan, belajar dan pembelajaran serta faktor-faktor yang mempengaruginya. Applied Microbiology and Biotechnology, 85(1), 2071-2079.

Thahir, A. (2012). Psikologi Kriminal. In Psikolgi Kriminal (Vol. 66, pp. 37-39).

Thamaria, N. (2016). Ilmu Perilaku dan Etika Farmasi (Vol. 66). Kementrian Kesehatan Republik Indonesia. 